\title{
Recognition of tacit skills: \\ Sustaining learning outcomes in adult learning and work re-entry
}

\author{
Karen Evans, Natasha Kersh, Seppo Kontiainen*
}

\begin{abstract}
This paper is based on the project "Recognition of Tacit Skills and Knowledge in Work Re-entry" carried out as a part of the ESRC funded Research Network 'Improving Incentives to Learning in the Workplace'. The network aims to contribute to improved practice among a wide range of practitioners.

The study has investigated the part played by tacit forms of personal competences in the education, training and work re-entry of adult learners. The models of learning produced within this study with the assistance of the Dynamic Concept Analysis computer program are used to provide a better understanding of individual case studies.
\end{abstract}

\footnotetext{
* Professor Karen Evans is Chair in Education (Lifelong Learning) and Head of the School of Lifelong Education and International Development at the Institute of Education, University of London

Dr Natasha Kersh is Research Officer at the Institute of Education, University of London

Professor Seppo Kontiainen was Professor of Adult and Continuing Education at the University of Helsinki and is now Visiting Professor at the Institute of Education, University of London
} 


\section{Introduction}

The part played by tacit skills and knowledge in work performance is well-recognised but not well understood. These implicit or hidden dimensions of knowledge and skill are key elements of 'mastery', which experienced workers draw upon in everyday activities and continuously expand in tackling new or unexpected situations. There is a bias in the tacit skills literature towards the understanding of expert knowledge as exercised in particular occupational or professional domains. In so far as worker biography is considered at all in this context, the literature tends to assume more or less continuous accumulation of know how and expert knowledge acquired in more or less continuous occupational biographies. This paper, based on the ESRC Teaching and Learning Research Network on Workplace Learning * argues that it is important to understand better the part played by tacit forms of personal competences in the education, training and work re-entry of adults with interrupted occupational or learning biographies. It aims to identify ways in which the recognition and deployment of tacit skills can be harnessed to strengthen their learning success and learning outcomes in new learning and working environments. The framework of concepts and issues has been published in Evans 2002, showing how approaches to 'tacit skills' have multiple roots in the literatures of epistemology (e.g. Polanyi 1967, Molander 1992), knowledge management (e.g. Johnson and Lundvall 2001) work process knowledge (eg Kusterer K 1978, Leplat 1990) and situated modes of cognition (eg Lave and Wenger 1991, Eraut 2000) . In this paper we concentrate on evidence from our latest empirical work, which has tracked adult learners into new work and learning environments. The importance of the workplace as a type of a learning environment has been emphasised in a number of recent research publications (eg Harris et al, 2001; Billett, 2000,2002; Rainbird (2000). A shift in emphasis away from institutionalised learning to workplace learning has been the key reform initiative in the last decade (Harris et al, 2001, p. 263). A qualitative analysis by Harris et al (2001) found that employers offered learning opportunities through a variety of strategies within non-formal learning settings such as staying with the employees on site, building on the closeness with them, encouraging them to think for themselves and try their own approaches before asking for help, adding explanation where appropriate or giving direct instructions. In respect of workplace learning in modern apprenticeships (Fuller and Unwin 2003) have shown that workplaces may be placed along a continuum which extends from restrictive to expansive, according to the ways in which their features (including culture, business goals and external pressures) combine to create environments which develop and expand (or restrict) the development of expertise. In assessing the applicability

\footnotetext{
* Economic and Social Research Council Award Number L139 2251005 directed by Helen Rainbird, Karen Evans, Phil Hodkinson and Lorna Unwin
} 
of this concept to the experiences of adults re-entering the workplace, we interpret the expansive workplace environment as one which is stimulating for adult workers as well as young people, and ask how far this expansiveness is related to recognition and development of tacit skills and opportunities to engage in non-formal learning.

The idea of individuals being able to transfer skills and competences between jobs in the interests of 'flexibility' has come to the fore as an instrument of 'lifelong learning' policy. Various forms of personal competences such as communication, interpersonal and problem solving competences have been portrayed as generic or transferable skills which are highly significant for individual effectiveness, flexibility and adaptability within the labour market (Kelly, 2001). At a European level, a scoping 'surveys and analysis' study supported by EU showed how the recognition of tacit forms of personal competences has been accommodated in different education and training models and national systems.(Hendrich et al, 2001). Five analytically defined model structures are shown in Table 1. All countries represent mixed systems although some features are more prevalent in some countries than others. Thus, the UK tends to be associated with dominance of market driven approaches, Germany with occupational labour markets and Portugal with strong non-formal sectors, for example. The UK market-led conditions were judged to be favourable for the appreciation of tacit forms of personal competences, given the lack of clearly structured systems of occupations at the lower and middle levels. Recognition of tacit forms of personal competences was also shown to be strongly gaining in importance in strong non-formal sector settings (e.g. Portugal) and in certificate-dominated settings like France, where the bilan de competence is becoming an internationally significant development. For the UK, this study concluded that although the conditions for recognition of tacit forms of personal competences were favourable, developments were 'severely restricted by the prevalent behaviouristic approach towards the identification and assessment of competences' (p.188). Despite this, there were important examples of good practice, particularly in college programmes originally designed for 'women returners'. While these broad characterisations do capture some important features of national contexts, a better understanding of the processes by which these skills are deployed and recognised in navigating changes in employment can only be understood by investigating individuals in context.

Considerable problems of definition surround the investigation of tacit dimensions of competence.(see Eraut 2000). While explicit knowledge and skills are easily codified and conveyed to others, tacit forms of personal competence are experiential, subjective and personal, and substantially more difficult to convey. The growing interest in their codification stems at least in part from a growing recognition that the tacit dimensions are very important in the performance of individuals, organisations, networks and possibly whole communities. Know-how is of particular significance for this discussion, referring to the ability to do things and involves complex linkages between skill formation and personal knowledge developed through experience. Much of the know-how people possess is acquired through practice or even painful experience. In this respect, 
this 'know how is taken so much for granted and the extent to which it pervades our activities is unappreciated' (Bjornavold, 2001, p. 24). Recognition of tacit forms of personal competences is also highly gendered. The extent to which this reflects differences between the sexes in the actual ownership of skills or differences in the ways in which they are ascribed to people in social settings is also the subject of much research and debate (see Heikkinen (1996) Billett (2002), Kampmeier et al 2003 ).

"Take in Table 1"

The nature of 'transfer' of competences between jobs and environments is also highly contested. For the purposes of this research, we hold that all skills and competences have both tacit and explicit dimensions. We regard tacit competences as partly structural and partly 'referential' (ie referenced to context), recognising that people do take things with them into new jobs and occupations, but not in simple ways". Naïve mappings of key skills from one environment into another are not a basis for occupational mobility. Even 'near' transfer into related activities is far from simple, leading to the recognition by activity theorists such as Engestrom $(1994,2000)$ that it is whole activity systems which count. For people with interrupted occupational biographies, this presents particular problems, particularly when they have spent extended periods away from the workplace and have no belief or confidence in their previous skills.

\section{Data collection and analysis}

To uncover the tacit skills of adults aiming to re-enter the workplace through further education and training, 61 adult learners following work re-entry courses in social care, management and transport sector jobs in 6 London region further/adult education colleges were selected as research participants. Different degrees of interruption were represented as follows: 29 (25 female $\{F\} 4$ male $\{M\})$ had experienced interruptions of more than 3 months, 17 of these (15F $2 \mathrm{M})$ had long term interruptions of more than one year. $32(18 \mathrm{~F} 14 \mathrm{M})$ had experienced minor breaks or changes of direction. The occupational areas were chosen for gender mix. The gender balance was typical for 'adult returners'; most of the longer term interruptions were for family reasons. Adults' learning experiences were researched through interview and observation (beginning October 2000), including tutor observations and recordings of learning processes, achievements and specific 'learning episodes' which involved tacit skills elicitation and use. The second stage of research (to June 2003) involved detailed longitudinal tracking of 30 of the research participants into their workplaces or other destinations, reviewing with them what they had gained from their learning and how this is built upon after they move into new working 
environments. Approximately three-fifths of those with interruptions of over 3 months, and all but one of those with minor changes, had re-entered work at the time of the follow-up. We have used structured elicitation approaches to elicit a wide range of tacit skills by asking adult learners about their life and work experiences and to relate these to their learning outcomes and achievements. Data collection also included semi-structured interviews with 20 tutors/training providers; 12 employers, 30 self-completion learner questionnaires (to check consistency of interpretations). Data have been analysed with the assistance of Nvivo and the Dynamic Concept Analysis (DCA) method (Kontiainen, 2002) has included the use of software to build conceptual models of individuals' learning.

\section{Deployment, acquisition and recognition of tacit skills.}

Our initial analysis of interview data showed how adults re-entering the workplace after completing their college programmes have previously acquired valuable personal skills not only from the workplace and formal education but also from considerable learning gained from a range of life experiences, through travel, in home and family settings, engaging in volunteer activities and overcoming various setbacks in life (see Evans, Kersh, Sakamoto, 2004). Such skills have strong tacit dimensions that may become explicit or visible to the holder when deployed or recognised in a relevant context or environment. Adult learners deploy a wide range of personal competences which have strong tacit dimensions, classified as follows in our earlier work:

1) Competences related to values and attitudes

2) Social and co-operative competences include a wide range of interpersonal abilities used in working with others.

3) Methodological competences include being able to handle multiple tasks and demands in complex and sometimes contradictory environments;

4) Practical and content-related competences refer to practical aspects of operating in (modern) work environments as well as subject matter relevant to work tasks

5) Learning competences include perceptiveness, openness to new experiences and reflective abilities

6) Strategic (or self-steering) competences include prioritising and planning.

Findings from the first stages of the research have also shown that males and females perceive their tacit skills differently. (see Evans et al 2004 for a fuller discussion)All of the female respondents with extended interruptions recognised, to some extent, personal competences they developed and used while running a household,caring for a family or overcoming setbacks, although they claimed that such skills are not recognised by the job market except in low status caring and 'women's' work. Males tended to disregard skills gained outside formal learning while attaching importance to 'formally acquired' skills. Employers' interviews confirmed that, while they see soft skills as important, these are often disregarded when they have been gained

\footnotetext{
* for a fuller discussion, see Evans et al 2002 and 2004
} 
in household settings. Our latest analysis has used learning episodes and conceptual model

-building to move beyond these broad comparisons to more detailed investigation of interrelationships between recognition of tacit skills, learning processes, gains and outcomes.. The learning episodes allowed us to triangulate learners' accounts, considering them within their own perspectives, their tutors' observations and in the context of their official grades.

\section{Learning episodes: facilitating learning success in a college environment.}

In the course of researching learning episodes which were significant in their use of tacit skills, we attempted to identify factors that make the connection between recognition of tacit skills (by tutors and learners themselves) and learning gains and outcomes visible. In other words we tried to identify how (or if) both students and tutors contribute to the process of the recognition of tacit skills in order to facilitate and improve students' learning success. Our findings have shown that the starting point of this process is that of awareness of students' 'hidden abilities' or tacit skills by tutors and students themselves. This contributes to further deployment and recognition of these skills in a learning environment. For Julia, a significant learning episode occurred early in the course. Her tutor, Jason, thought it very important to identify her prior skills and to make use of these skills in the setting of the course. The initial test scores provided the 'preliminary' source of information about her skills, such as math skills or language skills. However, as noted by the tutor, a number of important hidden skills such as ability to work with others, negotiation skills, managing conflicts or acceptance of self-responsibility, could become more explicit through employing different methods. He argues that specific activities on the course, such as teamwork for example, helped to make her tacit skills more explicit. He also maintains that teamwork was very important in her case for self-awareness and self-recognition of her own skills. Being a full-time mother for twelve years, Julia was not confident enough about her own skills. In order to boost her confidence, her tutor encouraged her to collaborate and help other students in the areas where he thought her skills were quite strong:

Yes, we certainly utilised them [her skills]. On the course we work fairly collaboratively, so she was at times working with other students who were having difficulties with particular things and we'd go into a huddle; so we'd work in that way, that everybody helps everyone in areas where they're strong and someone else might be weak, and vice versa.

Julia, herself, admitted that helping her fellow-students 'made her feel good', as for her that meant that her skills were being valued or recognised by someone else. As a result she felt motivated to use her skills and to develop them further. She also claims that recognition of her skills by her tutor encouraged her to 'work hard' on her course and - consequently - to improve her final test scores. Another investigation of significant learning episodes, in the case of Helen, yielded similar issues, in particular, that of improving learning success through recognition and awareness 
of tacit skills. However, our data indicates that in every single case different methods need to be employed in order to make tacit skills more explicit. What is successful in one case may not be very successful in another case, but success is generally associated with a relational emphasis in the learning and teaching approaches used. For example, in Helen's case, one-to-one tutorial help was the method employed by the tutor in order to identify and make her skills 'more visible' in the context of the course. For Helen, the fact that her tutor spent some time helping her encouraged her a lot.

\section{Learning episodes: making the transition between college training and workplace environments".}

The learning experiences of a student undertaking a practical job placement as part of her course were investigated to explore factors facilitating a student's learning success and achievements in an environment that combines elements of both workplace and college training. . Fiona has been assigned to take her practical work placement in the Business Centre of one of the colleges of further education in London. The college operates a business centre, which accepts six students who are undertaking a course in administration (NVQs Level I and II) in other colleges. The period of time they come for their job placements ranges from one month to an academic year. The important factor is that, with rare exceptions, they are all students from other colleges, and, therefore, they come to a completely new environment for them in order to gain some work experience. Their tasks include providing administrative services for tutors and members of staff, taking on a range of specific services such as preparing documents, word processing documents, photocopying, issuing and ordering stationery, sending faxes, making telephone calls, taking telephone messages, etc. The real challenge of their undertaking of job placements has to do with the fact that for many of them it is their first opportunity to test their skills into 'real workplace situations'. Making these skills visible is one of the primary goals for their supervisors, as smooth running of the business centre depends, in many ways, on how efficiently these students can perform their duties and how well they can co-operate with other members of their team. Ann, a co-ordinator, who supervised Fiona as well as other students, emphasised that lack of knowledge about their previous experiences and personal competences was one of the great impediments, which made it very difficult to both run the centre and facilitate the students' success:

And for me, that's one of the difficulties of managing the unit, but we always cope somehow. Once you've worked for a reasonable length of time, you begin to establish quickly how to pitch the kind of tasks you get them to do. But no, they come ... there's no interview. They're just coming into the Unit to increase their skills from whatever level they're starting at. 
Thus, identifying their skills and encouraging students to employ and develop them further is one of the challenges Ann faces. As well as in other cases (see above), Ann stresses that it is necessary to employ an individual approach in every particular case of learning. She describes Fiona as a very able female, who was both very determined and motivated towards further learning. However, when Fiona joined the centre, she could not fully deploy her personal and professional skills, as her command of English was poor at that time. Unlike Julia and Helen (see above), Fiona's case was not so much about making her aware of her own skills but about giving her plenty of opportunities to demonstrate her skills and make them visible to others. As Ann notes:

I think she had it in shed loads [her skills and competences]. She had lots of it. And what she needed, because her English was so poor, what she needed was the opportunity to demonstrate it, and of course it's difficult to demonstrate when people can see that your language communication skills are weak. But she was an extremely well organised person, learnt very quickly, very good at managing her own workload and really, I don't think there was ever any other member of the team that she didn't get on with. She was able to strike up a good working relationship at a working level and at a friendlier level, too. Very able young woman, very able.

Ann stresses that 'pushing her' her into deployment and demonstration of her skills was the most important method that facilitated Fiona's learning success. Apart from this, it also provided her with the opportunities to use it and to improve her understanding of the English language, including office vocabulary. Ann stresses that it was extremely important to make Fiona aware of the fact that her skills and competences were noted and recognised and were not being 'overlooked' because of her language problems. Delegating specific responsibilities to her, asking her to take part in a range of activities and encouraging her to take her own initiative were some of the methods Ann employed to make Fiona's skills visible to as many people in the office as possible.

Feedback is considered to be another important method that helps students to reflect upon their own experiences:

I think feedback to students is really important. They need to know what they have done that meets with approval and I don't miss opportunities if I possibly can to give them that. Also if there are things that they are doing that are counterproductive I try to make sure that they understand that this is not helpful and is going to impede their progress. I am particularly hot on feedback, whatever form it's got to take, whether it's positive or negative.

Fiona admitted that what she described as 'Ann's trust in her' really stimulated her towards further learning and skills acquisition. When Fiona joined the centre, she realised herself that her lack of English language skills could make it difficult for her to make her personal and professional skills visible to other members of staff. She stressed that with Ann's support she 
learned how to demonstrate her skills and competences within her work environment by taking initiative and volunteering to be involved in a range of activities. As a result, most members of staff gradually recognised her skills and abilities and were more than willing to collaborate with and to delegate specific duties to her. As Ann notes:

...they [other members of staff] recognised a shortfall in her English and whilst they had an interaction you knew that there was some doubt: 'will this work, because I'm not sure that this person's skills are strong enough to do this?'. By the time we were in the second part of our working arrangement, people were coming to me and saying isn't [Fiona] helpful. Doesn't she do this well. Could you ask her to come up and see me at such and such a time on such and such a day; that will be really helpful. So, you know, they were moved from a position where there was a bit of doubt and they might even have preferred to have dealt with somebody else to take the initiative to come to me and say that was really good, and she was really helpful and she delivered it on time....

Fiona's case provided an excellent example of collaboration between a student and a tutor to facilitate the student's learning experiences. Skills' recognition and making these skills visible were the central factors that facilitated Fiona's learning outcomes. Our evidence shows that tacit skills acquisition, deployment and recognition heightens self assurance where learning experiences have been positive or have involved overcoming setbacks and obstacles with positive outcomes. Learning outcomes is a complex concept that has both 'formal' and 'informal' dimensions. Learners' attitudes towards 'formal' and 'informal' learning outcomes change as they move between roles, settings and learning and working environments. At the beginning of their courses, adult students consider a 'formal outcome'- qualification or diploma - to be the most important learning result they expect from their course. Informal learning outcomes are often tacit in nature; adult learners do not necessarily recognize that they have gained anything valuable. However, as they progress in their course and move into learning environments which use and expand their skills (see below), they begin to recognize the value of 'informal' learning outcomes that are associated with self-assurance, increased capability, improved attainment, greater ability to exercise control over their situations and environments, and development of new attitudes towards learning/working.

We traced former students into their workplaces/places of further study or so-called 'forced situation', which in the context of our research means that they were either not able to find a job at all or were doing a job they did not like. The most successful cases of work re-entry were from the college course that combined theoretical studies with practical work placement. Adult learners taking part in the Business Studies Course which required them to spend several months at a job placement maintained that the practical skills they acquired while studying proved to be very useful. The fact that they gained this practical experience also made a favourable impression on their prospective employers at job interviews. It is well recognised that placements are important features of learning programmes for young people. For adults it is often assumed that their maturity and 
prior experience makes placements unnecessary, yet our findings indicate that adults benefit from the space to recontextualise their skills and find connections between their prior experiences and the affordances and constraints of new kinds of working environments.

\section{Tacit skills in the workplace: expansive or restrictive environments?}

Our interview data indicate that employees' learning success at work is strongly influenced by how they experience their working environments. In particular we identify ways in which the working environments are experienced as expansive or restrictive by adults re-entering the workplace after their college programmes. Workplace environments experienced as expansive facilitate further development and deployment of skills whereas environments experienced as restrictive are found in workplace settings that do little to encourage further professional training or development of new skills. Another feature of a restrictive environment is isolation at work when employees have a feeling that they are outsiders or mere observers. Conversely, expansive workplace settings are often associated with the feeling of being a part of a team at a workplace. Our evidence shows that the way adults experience their working environments depends on the following factors: (a) whether they describe their working environment as stimulating or dull; (b) whether they feel that their tacit skills are fully recognised by their employers; and (c) whether they have opportunities for further training, skills acquisition and career development at their workplace. All these factors are interrelated and influenced by each other. Our follow-up interviews indicated that an expansive environment is usually described as 'challenging', 'interesting', 'stimulating' or 'motivational'. Employees experience their working environments as expansive if they feel that their tacit skills are recognised by their employers or supervisors and especially if they are actively encouraged to deploy their skills. On the contrary, a restrictive workplace environment is usually perceived as 'boring', 'non-challenging', 'repetitive' or 'monotonous'. An interview with Stephanie for example shows that she experiences her workplace environment as dull or boring, not allowing for her personal and professional development. She argues that the environment at her workplace makes her feel 'a part of the furniture'. A similar experience is shared by Irene, who works as an administrative assistant in a small company. She emphasises that her responsibilities are very limited and not clearly defined and there are not many opportunities to deploy or develop her skills. Conversely, for those adults who describe their workplace as stimulating or expansive both recognition and deployment of tacit skills play an important part in facilitating such a positive environment.

What is more, employees can actually contribute to the development of a workplace environment which is expansive for them by taking initiative in many matters such as asking about opportunities for their further training or career development or even suggesting possible 
opportunities, learning from their colleagues or contributing to the planning, organising and conducting of various workplace activities. The interviews with both Diana and Mary show that they were very enthusiastic about undertaking further learning while doing their current jobs. Both of them took the initiative and convinced their employers that it would be very beneficial if they could undertake further training in the field of management. As a result they were allowed to do this and their employers paid for their courses. Cases show that people are able, to a certain extent and within the limits imposed by particular forms of work organisation, to make an input into the expansiveness or restrictiveness of their immediate workplace environment. While our cases did not have recourse to intermediary organisations, it is reasonable to suppose that representation and channels for employee 'voice' are more likely to facilitate the co-construction of expansive workplace environments than individuals trying to act alone and on their own behalf, or retreating into silence.

\section{Modelling of learning processes at work: individual case studies.}

Modelling of learning processes for learners with interrupted occupational and learning careers can identify ways in which recognition and deployment of tacit skills enhances learning experiences and outcomes as learners move between college and workplace settings, a primary goal of this research. The approach used, Dynamic Concept Analysis (DCA) (Kontiainen, 2002) is designed to analyse complex phenomena using conceptual models. An information matrix is constructed from available evidence on concept relations in adult and workplace learning to provide a basis for further building of models to describe the learning processes in individual case studies. The models show how the qualities (or attributes) describe a single case study and specify relationships between the concepts. They provide researchers' tools for case description and explanation. The components of workplace learning ${ }^{*}$ are divided among four main areas or categories, namely (1) learner; (2) skills deployment and recognition, (3) workplace environment and (4) outcomes. These four categories are discussed below.

\section{Category 1: Learner}

\section{Involvement (high-medium-low)}

This concept refers to a learner's degree of involvement within a learning environment or, in other words, 'the nature of involvement the learner has in a learning process' (Kontiainen, 2002). To what extent does a learner involve herself/himself actively in everyday learning activities? Does the

\footnotetext{
*We consider eleven concepts (or variables), namely involvement, confidence, autonomy, skills recognition, skills deployment, learning environment, learning attitudes, interaction, learning outcomes and workplace environment. Each variable has three attributes such as $a$ (positive, high or strong), $n$ (medium or neutral) and $b$ (negative or low). The models shows which of the attributes describe a single case study and specifies relationships among the concepts.
} 
learner assume an active or passive role within a learning environment? Our data indicate that adult learners' active (or strong) involvement is associated with their active participation in various activities within a learning environment.

\section{Confidence (high-medium-low)}

This concept refers to a learner's level of confidence. Our data show that, for adult learners, developing confidence is an important learning outcome or learning goal. There are visible interrelations between adults' levels of confidence and other concepts such as involvement, skills recognition and deployment. For example, learners who stressed the deployment of communication skills or 'getting on with people' in the college also demonstrated how this facilitated informal learning outcomes such as self-assurance, capability and confidence.

\section{Learning attitudes (positive-neutral-negative)}

This concept refers to adult learners' perceptions of their studies. Positive learning attitudes are associated with students' motivation and willingness to acquire new skills and knowledge or to develop their existing skills. Our interview data suggest that for adult learners, positive learning attitudes mean working hard, not being lazy and having a willingness to learn.

\section{Interaction (active-medium-passive)}

This concept refers to learners' willingness to work together and co-operate with other members of a group for the benefit of learning. Teamwork has been identified as an important characteristic of social interaction. Other types of social interactions that were named by adult learners are tutorial help, learning from others, communicating with fellow students and teaching others. The availability of these supports provides the context that mediates the impact of learning processes of individuals.

\section{Category 2: Skills recognition and deployment}

\section{Skills recognition (high-medium-low)}

This concept refers to level of recognition of adult learners' skills by their tutors, fellow students, employers, colleagues, etc. The important point to explore is the link between the recognition of tacit skills, learning processes and gains. How are these related? Do (and how do) the recognition of skills by students, tutors or employers impact on the learning process? Does it suggest, for instance, that if these skills are better recognised, then this will strengthen the confidence and self-assurance of students and enhance their learning gains? Our data show that recognition, acquisition and deployment of tacit skills are all interrelated processes. Students stress that recognition of their skills by others (e.g. tutors, employers, family) encourage (or would encourage) them to further develop their skills. 


\section{Skills self-recognition (high-medium-low)}

This concept explores to what extent adult learners recognise their own skills and personal competences. Self-awareness and self-recognition of an adult learners' own skills have been identified as an important component of adult learning.

\section{Skills deployment (positive-neutral-negative)}

This concept refers to the extent to which adult learners are able to deploy and develop their existing skills in a learning or workplace environment. On a practical level, those who have recently returned to attend courses at college have been shown to deploy tacit forms of personal competences such as time management, organisation and meeting multiple demands.

\section{Category 3: Learning environment/workplace}

\section{Learning environment (positive-neutral-negative)}

Our interview data indicate that a positive learning environment is associated with various features such as tutors' competence and support, well-developed curricula and training programmes, opportunities to deploy existing skills and to acquire new skills, etc. The concept 'learning environment' is applicable to any place where learning (either formal or informal) is taking place, including both college and workplace settings.

\section{Workplace (expansive-neutral-restrictive)}

This concept refers to opportunities provided by college/workplace environments in terms of skills deployment and acquisition as well as further learning in general. We identify the working/learning environments, which are experienced as restrictive (not facilitating further learning) or expansive (facilitating further development, deployment of skills) by adults re-entering the workplace after their college programmes . 


\section{Category 4: Outcomes}

Learning outcomes (positive-neutral-negative)

Our primary evidence from the follow-up interviews shows that students' learning outcomes are not restricted to formal results such as a certificate of qualification or diploma. As argued above, informal outcomes are those associated with self-assurance, increased capability, improved attainment, greater ability to exercise control over their situations and environments, and development of new attitudes towards learning/working. The data indicate that adults consider developing confidence to be an important learning outcome from their college and workplace training. More than half of those with long term interruptions in their occupational career recorded low levels of confidence initially, and only one a high level of confidence.

\section{Modelling of individual case studies.}

We attempt to analyse how learning processes could be understood in the context of interrelationships between various aspects of learning. The models of learning produced within this study are used to provide a better understanding of individual case studies within the general framework of adult learning. The examples below will demonstrate the potential of DCA approach for better understanding of the significance of tacit forms of personal competences in different learning environments.

\section{Case 1. Janice's case: Moving between college and workplace settings}

\section{Personal Background}

At the time of the initial interview Janice was at the beginning of a course called 'Certificate for Women in Management' that she undertook at a college of further education. Her previous work experience was mainly in administration including working for a cheque guarantee company and a publication company. After being made redundant in 2000 she could not obtain a permanent full-time position for two years. She has been working for various agencies, doing short-term jobs ranging from two weeks to three months in length. She decided to undertake the course because she wanted to develop her skills in management and administration. Another reason for taking the course was that she wanted to develop her confidence and self-assurance. She admitted that after losing her job her confidence level was gradually decreasing. Her confidence decreased to a very low level because she could not find any employment for a substantial period of time. She also insisted that lack of interaction with other people resulted in her 
loneliness and isolation. By the time of the follow-up interview, nine months later, the course had helped her to develop many valuable skills and competences, both technical and personal, which generated a sense of confidence and resulted in a successful job application to work in the administration department at a Magistrate's Court.

In Janice's case study the comparison between models of her college and workplace experience shows that completing a course programme enabled growth in confidence and involvement as well as autonomy in deployment of skills.

\section{College related experience (see Model 1.1).}

"Take in Model 1.1"

\section{(1) Learner.}

Model 1.1 represents the learner's college based experience. It shows that at the time of the initial interview, her confidence and involvement were low (1b, 2b), thus contributing to her passive social interaction (4b).

\section{(2) Skills deployment and recognition.}

The model indicates that medium recognition and deployment of tacit skills are interrelated processes (5n, 6n), as the learner does not feel motivated to deploy her tacit skills because they are not fully recognised. Furthermore, low self-recognition (7b) of her skills also contributes to the learner's low confidence (2b) and low involvement (1b) in her course activities as well as to passive social interaction (4b).

\section{(3) Learning Environment.}

The learner experienced some elements of her general learning environment as positive (8a) in expansive ways.

\section{(4) Learning outcomes.}

Stimulating learning environment facilitated Janice's positive learning outcomes (10a) towards the end of her course.

\section{Workplace related experience (Model 1.2).}

\footnotetext{
"Take in Model 1.2"
} 


\section{(1) Learner.}

At the time of the follow-up interview (see Model 1.2), it was apparent that towards the end of her course she developed her confidence (2a), which was facilitated further by an expansive workplace environment. The second model shows that positive interrelationship between concepts has visibly developed. Her involvement is high (1a) as she participates in many workplace activities. As the model indicates, her confidence (2a) displays an important part, facilitating other concepts (e.g. 1a, $3 \mathrm{a}, 8 \mathrm{a})$. She feels that her personal confidence and skills are being fully utilised in her work environment. She also refers to her college experience, stressing that elements of that learning environment helped her to build up her confidence towards the end of her course.

\section{(2) Skills deployment and recognition.}

At her workplace her skills were recognised by her supervisors and this facilitated her in deploying them (5a, 6a). The Model 1.2 shows that high skills deployment (5a) and high skills recognition (6a) are interrelated concepts that facilitate her confidence (2a), involvement (1a) and her attitudes (3a).

\section{(3) Workplace/Learning Environment.}

Her skills were facilitated further in the new expansive workplace environment (9a). Positive elements of her expansive workplace environment (such as recognition and deployment of her skills, involvement, interaction, etc.) strengthen her confidence and learning success.

\section{(4) Learning Outcomes.}

Her involvement (1a), confidence (2a), learning attitudes (3a), active social interaction (4a), deployment (5a) self-recognition (7a) and recognition of her skills by her manager (6a), positive learning environment and workplace environment (8a, 9a) facilitated her informal learning outcomes, especially those associated with increased capability, improved attainment and greater ability to exercise control over various situations and environments. She is very determined and motivated in terms of the acquisition of new skills, abilities and knowledge.

\section{Case 2. Tracey's case: workplace experience (see Model 2).}

"Take in Model 2"

Personal Background

Tracey is a separated mother with seven children. Because of her family commitments it was difficult for her to obtain a qualification or to develop her career early in her life. Her previous work experiences included working in the office of a scaffolding company for two years. She left her job to start a family and stayed at home for 15 years. She decided to return to studying 
when her youngest children started full-time schooling. Because she wanted to work in administration she started taking a range of courses to develop her administrative skills, such as 'Introduction to Computers', 'Introduction to Word-processing and Spreadsheets'. At the time of the initial interview she was close to completion of her course in Business Administration GNVQ Level 2 in a college of further education. She also undertook a work placement in a police authority as a part of her college training. At the end of her work placement she was offered a full-time job by the Police Department

\section{(1) Learner.}

Tracey does not personally involve herself very strongly in learning activities at the workplace (1n). She is not confident enough to take the initiative or to interact more actively in her workplace ( $2 \mathrm{n}$, 4n). However, her learning attitudes are positive (3a); when her employers offer her the chance to undertake further training in a college of further education she gladly accepts.

\section{(2) Skills deployment and recognition.}

Tracey maintains that she is able to deploy her personal skills at her workplace (5a). This facilitates further development of her skills and contributes to her perception of the workplace environment as expansive (9a). However, she does not feel that her skills are fully recognised (6n). Though even partial recognition of her skills by her manager and her colleagues encourages her to use them within her workplace (6n, 5a).

\section{(3) Workplace/Learning environment.}

Tracey experiences the general learning environment at her learning environment at the workplace neutral (8n). She maintains that this is mainly due to the fact that there are not opportunities for further training within her workplace. However, she experiences the general working environment (9a) as expansive as there are many opportunities to deploy her existing skills (5a).

\section{(4) Outcomes.}

Tracey achieved some gains with respect to increased self-assurance and capability. These 'medium-level' learning outcomes resulted from her moderate levels of involvement (1n), confidence (2n), interaction, skills recognition (6n) and self-recognition (7n) and neutral learning environment $(8 n)$.

\section{Case 3. Ahmet's case: expansive workplace environment (see Model 3).}


"Take in Model 3"

\section{Personal Background}

Ahmet works as an overnight porter in a big hotel in London. He came to England from Morocco several years ago. Since then his experiences have included doing short-term jobs such as sandwich-making, catering and cleaning. At the time of the initial interview he was participating in the Training Programme of a major transport company offered through one of the colleges of further education, because as he said he wanted to 'do something different and to acquire new experience'. This programme involves an intensive training programme in math, English and application form and interview techniques for adults wishing to apply for the position of station assistant. Those who successfully pass a test at the end of the programme are offered a job interview. Ahmet had passed the test and been invited for a job interview, but did not get the job. The fact that he did not get a job with the transport company has not affected his confidence or self-assurance. He is very motivated towards learning, taking various courses in colleges of further education as well as participating in workplace training. He mentions that employees are able to undertake regular workplace training in health and safety as well as fire training. What is more, his manager has offered him one-to-one training in order to develop his computer skills as well as customer service skills. The purpose of this training is to promote Ahmet to a position as a receptionist in this hotel. He is clearly enthusiastic about his workplace learning as well as about good prospects for his career development in the hotel. He notes that he is especially encouraged by the fact that his manager recognises and values his personal or tacit skills such as communication skills, confidence, customer care skills and foreign language skills. All these factors motivate him towards further workplace learning.

\section{(1) Learner.}

Ahmet is confident within his workplace environment (2a). His social interaction with other colleagues within the workplace is not very strong $(4 n)$, thus reducing his involvement (1n). He is not necessarily very active and independent (1n) and prefers to rely on his manager's advice and instructions. However, this 'dependency' has resulted in higher skills recognition (6a) and deployment (5a) as Ahmet's manager provides one-to-one workplace training for him with the purpose of giving him more responsibilities within the workplace. His learning attitudes are extremely positive (3a) and he uses any opportunity offered by his employers to learn new skills and competencies at his workplace. His high confidence (2a) is one of the central concepts facilitating his positive learning attitudes (3a), skills deployment (5a), recognition (6a) and self-recognition (7a). 


\section{(2) Skills deployment and recognition.}

Ahmet feels that his skills are fully recognised by his employers and this encourages him to deploy them at the workplace (5a, 6a). Skills recognition and deployment is also facilitated by his confidence (2a) and expansive workplace environment (9a).

\section{(3) Workplace/Learning environment.}

Ahmet experiences his workplace environment as an expansive one, providing opportunities for further training and professional development (8a, 9a). Recognition of his personal tacit skills (6a) and opportunities to deploy them (5a) contributes greatly to his perception of the workplace environment as expansive (9a).

\section{(4) Outcomes.}

Stimulating workplace environment, skills recognition and deployment, and learning attitudes contributed to the development of positive informal outcomes (10a). Ahmet feels that these factors helped further to develop his confidence and self-assurance. His positive learning outcomes result from his high confidence (2a), positive learning attitudes (3a), high skills deployment (5a), recognition (6a) and self-recognition (7a) positive learning (9a) and workplace (10a) environments.

\section{Comparing cases}

Ahmet's case, together with the others we have outlined, shows how conceptual modelling allowed us to carry out systematic case analysis. When compared and combined with standard qualitative analysis of the full set of data, the evidence shows the importance of recognition and deployment of tacit skills in learning/workplace environments. Learners with more continuous occupational biographies generally recorded higher initial levels of confidence in their personal competences than those with substantial interruptions, except in cases where recent work experiences had been poor. The use of prior skills in the cases of adults with significant interruptions in their occupational biographies can be contrasted with those of adults with more continuity in their careers and identities. Drawing out of tacit elements to 'make them visible' is of considerable importance in the case of adults with interrupted occupational biographies; it is through self recogniton and recognition by others of their hidden skills and abilities that adults seeking to re-enter work after a break or changing direction gain the self assurance and confidence to negotiate new environments and deploy those skills. For those with more continuous occupational biographies who move between workplaces and positions, prior skill and knowledge are not simply transferred even though they are more 
readily recognised by the holder as being of direct relevance; they also have to be operationalised in the culture of the new context. Self-awareness of personal competences affects the ways in which people explore the affordances and constraints of the new environment. Case analysis and comparison showed how adults' learning processes are negatively affected where recognition and deployment of tacit skills of an adult is low or negative. Conversely, positive deployment and recognition of these skills sustains learning and contributes to learning outcomes. The starting point of this process is that of awareness and self-awareness of learners' hidden abilities or tacit skills by tutors and students themselves. Furthermore, recognition and utilisation of tacit skills in stimulating, 'expansive' learning environments sustains learning outcomes and facilitates the process of work re-entry. Systematic case comparison showed that employees experienced their workplaces as either expansive or restrictive depending on the following factors: (1) types of workplace environment: stimulating versus dull; (2) recognition of employees' skills and abilities; (3) opportunities for workplace training and career development. There are strong links between the recognition of tacit skills, learning processes, gains and outcomes.

\section{Conclusions and future directions.}

In this paper we have attempted to describe and analyse the ways in which recognition and deployment of tacit skills may sustain learning outcomes and facilitate expansive workplace environments. Our analysis, using a version of Kontiainen's Dynamic Concept Analysis (2002) shows that harnessing tacit skills in stimulating and expansive working environments sustains learning outcomes and facilitates the process of work re-entry. Adults re-entering the workplace after their college programmes may experience their working environments as expanding, consolidating or undermining their learning gains. Environments which are experienced as giving recognition to and supporting deployment of tacit as well as explicit skills, facilitate further development. The parts played by the workers in creating environments which support their deployment of skills, and their further learning are contributory factors. The way employees experience these environments often has to do with the feeling of being a part of a team, allowing them to deploy their tacit skills in ways which enhance their confidence and self-assurance, whereas experience in environments which undermine learning gains is often associated with being an outsider or mere observer in the workplace.

Standard qualitative analysis extended by modelling of individual cases and systematic case comparison is enabling us to elaborate a larger conceptual model of the significance of 
tacit skills recognition in adult learner biographies. Personal competences gained from various life experiences are deployed and developed in both college and workplace settings. The acquisition of these skills is often tacit in nature and therefore individuals do not necessarily recognise that they have gained anything valuable. However, these previously acquired skills often become a central part of a learning process when they are deployed and developed in new learning and workplace environments. Tacit skills development is non-linear, and the use of tacit skills is situation-specific: tacit skills may lead to success in one context but not necessarily in another. The recognition of tacit skills contributes to their transformation from the tacit to the explicit dimension in ways which can facilitate positive learning outcomes for adult learners, such as those associated with self-confidence, increased capability for improved attainment and greater abilities to exercise control over their situations and environments. This is particularly important for those with substantial interruptions in their occupational biographies. Recognition (by self and others) of tacit dimensions of competences developed or influenced through prior activity need not fall into the trap of assuming that all that is tacit is good. Prejudices, poor practices and uncritical intuition (Neuweg 1999) can become open to challenge in making the transformation from the tacit to the explicit dimension, and this also can become part of the transformation. Beyond 'transfer of skills' we emphasise the agency of the whole person (see also Lobato 2003) and learners' personal processes within social settings which structure their experiences, including the way in which the person brings his or her tacit skills into play in constructing and negotiating the affordances and constraints of new environments. This analysis has been elaborated further in Hodkinson et al 2003 as a major thematic outcome of the ESRC Research Network on Incentives to Learning in the Workplace*.

The interpretation of the conceptual DCA models gives an insight into the circumstances in which learning takes place and contributes to a better understanding of how interventions can be made in learners' programmes. More broadly, findings suggest that approaches which emphasise the relational aspects of teaching and learning, and pay attention to the construction of learning environments which value and draw out tacit skills can improve learning success. As well as providing a research tool, a simplified version of conceptual model building can be used with practitioners (programme designers, tutors, trainers, mentors, human resource developers and learners themselves) in ways that enable them to reflect upon and change their own concepts and approaches, including the creation of learning environments. The further development of methods piloted in this study is now taking place through a European consortium of researchers and

\footnotetext{
* see Hodkinson P, Hodkinson H, Evans K and Kersh N with Fuller A Unwin L and Senker P, The Significance of Individual Biography in Workplace Learning submitted to Studies in the Education of Adults July 2003
} 
practitioners working to produce tools which can be used the self-evaluation and development of personal competences in a wide range of continuing vocational training settings. 


\section{References}

Billett, S. (2000), 'Performance at Work: identifying smart work practice', in R. Gerber and C. Lankshear (eds), Training for a Smart Workforce (Routledge, London).

Billett, S. (2002), 'Critiquing workplace learning discourses: participation and continuity at Work', Studies in the Education of Adults, 34 (1), 56-67.

Bjornavold, J. (2001), 'Making Learning Visible: identification, assessment and recognition of non-formal learning', Vocational Training, No. 22, pp. 24-32.

Engestrom, Y. (1994), Training for Change: New Approach to Instruction and Learning in Working Life (International Labour Office, Geneva).

Evans, K. and P. Hodkinson, L. Unwin (eds) (2002), Working to Learn: transforming learning in the workplace (Kogan Page, London).

Evans, K. and N. Kersh, A. Sakamoto (2004), 'Learner Biographies: Exploring Tacit

Dimensions of Knowledge and Skills', in press in H. Rainbird, A. Fuller and

A. Munro (eds), WorkplaceLearning in Context (Routledge, London).

Eraut, M. (2000) 'Non-formal learning, implicit learning and tacit knowledge', in F. Coffield (ed), The Necessity of Informal Learning (Policy Press in association with the ESRC Learning Society Programme, Bristol).

Fuller, A. and L.Unwin (2003, in press), 'Learning as Apprentices in the Contemporary UK Workplace: creating and managing expansive and restrictive participation', Journal of Education and Work, 16:4.

Harris, R. and P. Willis, M. Simmons, E. Collins (2001), 'The Relative Contributions of Institutional and Workplace Learning Environments: an analysis of apprenticeship training', Journal of Vocational Education and Training, Vol. 53 No. 2, pp. 263-278.

Heikkinen, A (1996), Gendered History of Vocational Education (University of Tampere, Tampereen yliopisto).

Hendrich, W. and G. Heidegger, K. Evans, E., Figueri, N. Patiniotis (2001), Tacit - Key Project Final Report (University of Flensburg/European Commission, Brussels).

Johnson, B. and B.A. Lundvall (2001), Why all this fuss about codified and tacit knowledge? (DRUID International Conference, Aalborg).

Kampmeier, A. (ed) (2003), Gender and Qualification, Fifth Framework Project Final Report, (European Commission, Brussels).

Kelly, A. (2001), 'The Evolution of Key Skills: towards a Tawney paradigm', Journal of Vocational Education and Training, Vol. 53 No. 1, pp. 21-35. 
Kontiainen, S. (2002), Dynamic Concepts Analysis (DCA): Integrating Information in Conceptual Models (Helsinki University Press, Helsinki) (the book and a computer program available at http://www.edu.helsinki.fi/DCA/).

Kusterer, K. (1978), Know-How on the Job: The Important Working Knowledge of 'Unskilled' Workers (Westview Press Inc, Boulder,Co).

Lave, J. and E. Wenger (1991), Situated Learning: Legitimate Peripheral Participation, (Cambridge University Press, New York).

Leplat, J. (1990), 'Skills and tacit skills: a psychological perspective', Applied Psychology: An International Review, 39 (2), pp 143-54.

Lobato, J (2003), 'How design experiments can inform a rethinking of transfer and vice versa', in Educational Researcher Online, American Educational Research Association, Vol 32, No 1, Jan/Feb 2003 pp. 17-20.

Neuweg, G. H. (1999), Konnerschaft und implizites Wissen. Zur lehr-lerntheoretischen Beeutung der Erkenntins- und Wissentheorie Michael Polanyis (Munster, Berlin).

Polanyi, M. (1967), The Tacit Dimension (Doubleday, New York).

Rainbird H (2000) Training in the Workplace: Critical Perspectives on Learning at Work (Macmillan, Basingstoke). 